\title{
A SURVEY OF COMPUTER AIDED DIAGNOSIS (CAD) OF LIVER IN MEDICAL DIAGNOSIS
}

\author{
DR SHOAIB FAROOQ $^{1}$, ZOYA KHAN ${ }^{1}$ \\ ${ }^{1}$ Department of Computer Sciences, University of Management and Technology, Lahore Pakistan \\ Email: shoaib.farooq@umt.edu.pk
}

\begin{abstract}
In the modern World, diseases may occur at any time. Early diagnosis can prevent the serious consequences of the disease. The Computer Aided Diagnosis has very positively influenced the medical field. It helps the Radiologists to diagnose the diseases very quickly, precisely and accurately. The earlier diagnosis can help doctors to cover further spreading of the disease and to overcome at all. In this paper presented the following step to implements the Diagnosis process including the image preprocessing, Feature Extraction, Segmentation and classification. There are different techniques used in Image Segmentation like Fuzzy-C-Mean (FCM) Algorithm, Thresholding, Watershed Clustering Method and Region Growing etc. Feature extraction is the second phase that includes the calculation of different features of segmented lesion. It transforms the data that is in high-dimensional space to some extent of lesser dimensions. This is the final phase the classification phase that which is deals the Measurement of feature that are used the input to support the vector machine in last classify the lesion. This paper works of Computer Aided Diagnosis on liver lesion has briefly described.
\end{abstract}

Keywords-CAD, FCM, Fuzzy, Clustering, Region Growing, Watershed, thresholding, Region of Interest, segmentation, MRI, CT scan.

1. Introduction. Liver is very significant part of a human body that performs the vital functions in our body however diseases may occur any time. Liver is badly affected with cancer so early diagnose can prevent cancer which is in most cases cause ultimate death. Liver cancer diagnosis may include Blood Tests, Image Scan and Biopsy. Computer Aided Diagnosis has become a broad field in medical research in last few years and has played vital role in the medial diagnosis field [1]. Computer aided classification is dynamic field of research which provides the immense methodologies of medical imaging. With the help of Computer aided classification techniques, we can improve the diagnosis accuracy in classification, detecting or segmenting liver lesions
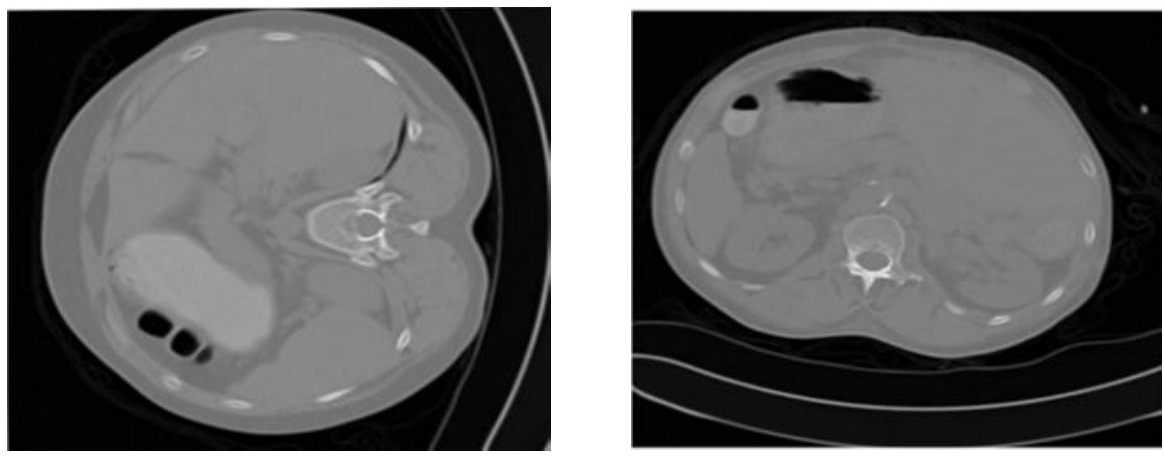

Figure-01: Liver CAD Images

According to the recent statistics on cancer disease it is reported that cancer is third most diagnosed disease and second most leading cause of human death. The statistics also shows that the patients who are diagnosis with cancer may die in less than six months $[4,5]$. There are a number of computer aided image diagnosing tools and technologies like X-rays, CT Scans and MRI capable to diagnose liver cancer and many more[2]. 
Every computer aided diagnostic classification method consists of different phases. They have including in following steps e.g Image Segmentation, Feature Extraction, Image Pre-processing and classification. Contrast of the image is enhanced in image pre-processing phase. Segmentation deals detection and region of interest (ROI) from the other parts of the liver image. Feature extraction transforms the data in high-dimensional pixels to lesser dimensional pixels acceptable to the algorithm. Feature extraction is the most important and challenge us phase in $\mathrm{CAD}$ [3]. In classification, the segregation of blood vessel information is taken place from the image being examined. Generally in classification the resultant of feature extraction is fed into Support Vector Machine (SVM) by labeling different parts of the liver lesion such as Benign and Malignant [6].

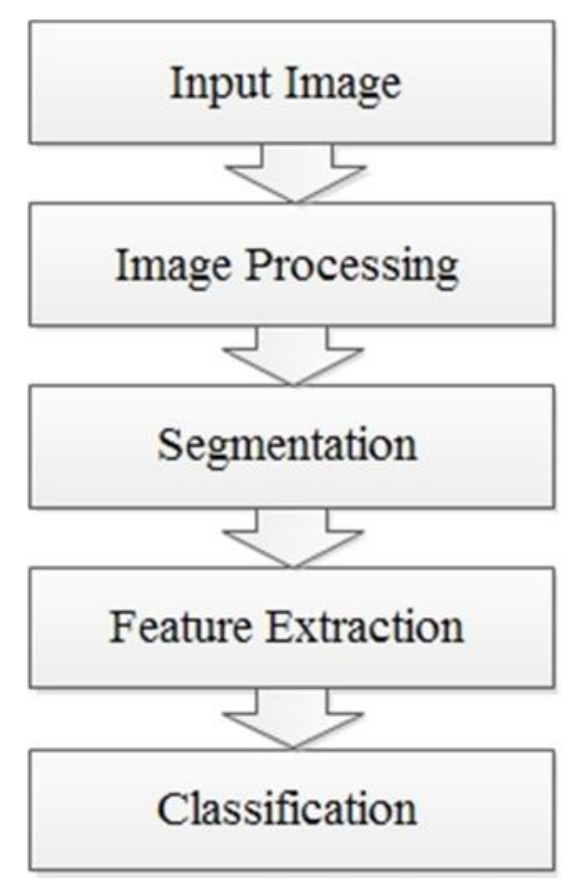

Figure-02: Typical Computer Aided Diagnose Process Hierarchy

There are a number of techniques used for image segmentation. Most popular of these are.

Fuzzy-C-Means (FCM). Fuzzy-C-Means (FCM) is a clustering mechanism in which one data piece belongs to different data clusters. It mainly is involved in pattern recognition process. This techniques works on the assignment of clusters to each data point on the basis of the space between data point and relevant cluster. This algorithm involves different iterations where each membership and cluster is updated after each iteration in accordance with formula associated with the algorithm of FCM technique [7, 8].

Thresholding. Thresholding provides simplest method of the image segmentation by creating binary images from grayscal images. Thresholding technique has two categories. Global and local or adaptive Thresholding. The global thresholding the involve single value threshold image whereas local thresholding involves the multiple values are each threshold.

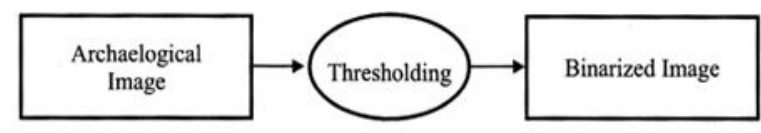

Figure-03: Thresholding Process in input/output

Watershed. Watershed clustering method works on the intensities of the image in order to classify the image. Watershed relates to the parameters of contiguous catchment basins the water drops.

Region Growing. An image segmentation technique that performs segmentation on the basis of regions in the image in $\mathrm{CAD}$. It is also called the pixel based image segmentation by considering primary seed points. It scans the 
adjoining pixels of seed point and examines and adds the adjacent pixels of the seed point to the region which is being processed under this algorithm. The following table shows a brief comparison based on advantages and disadvantages of these segmentation algorithmic techniques $[9,10]$.

Table-01: Segmentation Techniques Comparison

\begin{tabular}{|c|c|c|}
\hline Technique & Advantage & Disadvantage \\
\hline $\begin{array}{l}\text { Fuzzy C means } \\
(\mathrm{FCM})\end{array}$ & $\begin{array}{l}\text { - Very simple implementation } \\
\text { - Fast and efficient. } \\
\text { - Better than K-Means } \\
\text { - Good convergence }\end{array}$ & $\begin{array}{l}\text { - Main disadvantage of this algorithm is its } \\
\text { output depends upon the partitions used in } \\
\text { segmentation. } \\
\text { - Noise sensitive } \\
\text { Difficult to determine fuzzy members }\end{array}$ \\
\hline Thresholding & $\begin{array}{l}\text { - Useful in grey scale images and for } \\
\text { image linearization. } \\
\text { - Prior image information not required } \\
\text { - Used in real time applications } \\
\text { - Simple and fast implementation }\end{array}$ & $\begin{array}{l}\text { - This algorithm does not work on all MRI } \\
\text { images because of intensity variation in } \\
\text { image. } \\
\text { - Noise sensitive } \\
\text { - Threshold selection is crucial } \\
\text { - }\end{array}$ \\
\hline Watershed & $\begin{array}{l}\text { - Classify the pixels of image based on } \\
\text { their intensities. }\end{array}$ & $\begin{array}{l}\text { This algorithm separate the pixels based on } \\
\text { their intensities which may lead to the over } \\
\text { segmentation. }\end{array}$ \\
\hline Region Growing & $\begin{array}{l}\text { - Separates the region that has same } \\
\text { properties according to the given } \\
\text { criteria. } \\
\text { - Provide exact image with clear edges. } \\
\text { - Small number of seed points required. } \\
\text { - Multiple criteria at same times. }\end{array}$ & $\begin{array}{l}\text { - Expensive to implement } \\
\text { - This algorithm is very sensitive to the noise. } \\
\text { - This algorithm may lead to the gradient } \\
\text { problem. } \\
\text { - Local method with no global views. } \\
\text { Noise sensitive }\end{array}$ \\
\hline
\end{tabular}

Table-02: Comparison of Image segmentation methods

\begin{tabular}{|c|c|c|c|c|c|}
\hline Parameter & $\begin{array}{l}\text { Threshold } \\
\text { based } \\
\text { Method }\end{array}$ & $\begin{array}{l}\text { Region based } \\
\text { Method }\end{array}$ & $\begin{array}{c}\text { Discontinuit } \\
\text { y bused } \\
\text { Method }\end{array}$ & $\begin{array}{l}\text { Cluster } \\
\text { bused } \\
\text { Method }\end{array}$ & $\begin{array}{l}\text { Fuxry C- } \\
\text { means } \\
\text { Method }\end{array}$ \\
\hline $\begin{array}{l}\text { Sputial } \\
\text { Information }\end{array}$ & Ignored & Considered & Ignored & Considered & Consiblered \\
\hline $\begin{array}{l}\text { Region } \\
\text { Continuity }\end{array}$ & Reasonable & Cood & Reasonable & Reasonutle & Good \\
\hline Speed & Fast & Slow & Moderate & Fast & Moderate \\
\hline $\begin{array}{l}\text { Computation } \\
\text { Complexity }\end{array}$ & Less & Ropid & Moderate & Rapid & Moderate \\
\hline Automaticity & Semisuto & Semiauto & Interactive & Automatic & Automatic \\
\hline $\begin{array}{l}\text { Noise } \\
\text { Resistance }\end{array}$ & Less & Less & Less & Moderate & Moderate \\
\hline $\begin{array}{l}\text { Multiple } \\
\text { Otyect } \\
\text { Detection }\end{array}$ & Poot & Fair & Poor & Fair & Fair \\
\hline Accuracy & Moderate & Fine & Moderate & Moderate & Moderate \\
\hline
\end{tabular}

2. Related Work. Hussein Alahmer, Amr Ahmed proposed a method that involves the implementation of FCM Clustering Algorithm in which the CT Grey Scale Image is splatted into three classes. After using morphological operation the lesion is separated from other organs. It involves the multiple ROI in which $\mathrm{R}_{0}$ is ROI, $\mathrm{R}_{1}$ is inner part 
of lesion and $\mathrm{R}_{2}$ is outer boundary of lesion.

$$
\mathrm{R}_{\mathrm{o}}=\mathrm{R}_{1} \mathrm{U} \mathrm{R}_{2}
$$

The intensity, texture and shape of the image are also considered in this model. It is the last stage in which the data from the feature extraction is used to feed the SVM which label the image as Benign and Malignant. The Devendra Joshi are introduce the theory which is consider are region of interest (ROI) by the tumor in liver lesion for adapter thresholding detection. The entire image is divided into sub an image in which the segmentation is achieves by splitting and merging steps. Then the watershed method is adapted in further segmentation. This method first computes the segmentation function and then it computes foreground markers. In the next step it computes the background markers and further modification take place in next step. At the end it colors the output images of watershed method as purple, green and red.

Vincey Jeba Malar.V,Saravana Kumar.E proposed a new method of CAD. In this technique he used the Region Growing method for image segmentation. In this method it will grow from the seed and further compared with the neighborhood values. The result of this step will be separation of liver tissue from the rest of organs. In feature extraction phase the data is simplified from large amount to the extent to be used according to available resources. In the classification phase the Hidden Markov Model (HMM) is used. Aur'eline Quatrehomme, Ingrid Millet proposed a method which used Media Contrast Injection (MCI) for the segmentation process which involved pictures in 4 phases. First phase is called Pre-processing, second phase is Arterial phase, third is Portal phase and the last phase is Late phase. The difference in properties of different phases results in segmentation of the lesion. Then used the Unser histogram, Law measures, Gaussian Markov Random Field Measures and Histograms Statistics method for segmentation. It is the last stage in which the data from the feature extraction is used to feed the SVM which labels the images. The Classification validation involved the Leave on Out technique [4].

The O. Fekry Abd-Elaziz, M. Sharaf Sayed Proposed a new technique of CAD. These technique are used to implement the segmentation of region growing method. In the start seed point and properties are compare the neighboring pixels. In next segment he utilized the sectioned liver area and obtain approximation of tumor locale utilizing the past decided estimations of the liver region obtained from CT image histogram [6].

Luyao Wang Et Al proposed a hybrid method to solve the classification problem in liver lesion. In this method the Region of Interest (ROI) was defined by the experienced radiologist by using CT scan images and then the features. In the first stage statistics, spatial grey level dependence matrix, grey level run length matrix and grey level difference matrix were extracted from the ROI's. In the last stage they use multiclass SVM to classify haptic tissue into primary hepatic carcinoma, hemangioma and normal tissue using one against all and one against one comparison[7].

S.S Kumar and Moni proposed a CAD method to classify the tumor into Benign and Malignant. They used FCM Clustering method to detect the tumor region from the segmented liver image. In the feature extraction phase they use Fast Discrete Curvelet Transform Method to extract feature from each of ROI's. In the classification phase, they use Feed Forward Method to classify the tumor into Benign and Malignant [8 9].

Gletsos Miltiades proposed a method which consists of two modules. Feature Extraction and the data from the identification of different ROI's are then fed to the Feature Extraction [9].

Jae-Sung Hang Et Al proposed a method of computer aided diagnosis using Fuzzy-C-Means (FCM) for clustering algorithm to segment the tumor. In next phase he used features like area, circularity and minimum distance from liver boundary to tumor for extraction. In the last phase he used Naïve classifier to classify normal and abnormal slices [11 13].

K.Mala and V.Sadasivam proposed a method which automatically detects the tumor region from the CT image. He uses the sequential backward selection technique to reduce the features. In the classification phase, he uses the probabilistic neural network to classify the tumor in hepatocellular carcinoma, cholangiocarcinoma, hemangeoma and hepatoadenoma $[12,14,15]$.

3. Analysis

Table-03: Comparison of different techniques

\begin{tabular}{|c|c|c|c|}
\hline Author & Method & Result & Purpose \\
\hline Hussein Alahmer, & $\begin{array}{l}\text { FCM clustering for } \\
\text { segmentation }\end{array}$ & $\begin{array}{l}98 \% \text { accuracy on } 60 \\
\text { cases }\end{array}$ & $\begin{array}{l}\text { Classificati } \\
\text { on of liver } \\
\text { lesion }\end{array}$ \\
\hline Amr Ahmed & $\begin{array}{l}\text { Feature Extraction for } \\
\text { multiple ROI. } \\
\text { Classification by SVM }\end{array}$ & & \\
\hline DevendrA Joshi & Adaptive threshold and & Adaptive & Detection \\
\hline
\end{tabular}




\begin{tabular}{|c|c|c|c|}
\hline & $\begin{array}{lr}\text { watershed method } & \text { for } \\
\text { segmentation } \\
\text { comparison }\end{array}$ & $\begin{array}{l}\text { Thresholiding } \\
\text { method is easy and } \\
\text { better than watershed } \\
\text { method }\end{array}$ & $\begin{array}{l}\text { and } \\
\text { segmentatio } \\
\mathrm{n} \text { of tumor. }\end{array}$ \\
\hline $\begin{array}{l}\text { Vincey Jeba Malar.V, } \\
\text { Saravana Kumar. E }\end{array}$ & $\begin{array}{l}\text { Region growing technique } \\
\text { for segmentation } \\
\text { HMM for classification. }\end{array}$ & $\begin{array}{l}96.5 \% \text { detection on } \\
100 \text { cases. }\end{array}$ & $\begin{array}{l}\text { Classificati } \\
\text { on of liver } \\
\text { lesion }\end{array}$ \\
\hline $\begin{array}{l}\text { Aur'eline } \\
\text { Quatrehomme, } \\
\text { Ingrid Millet }\end{array}$ & $\begin{array}{l}\text { Media Contrast Injection } \\
\text { for segmentation } \\
\text { GMRFM, Histograms } \\
\text { Statistics for feature } \\
\text { extraction } \\
\text { SVM is used to label the } \\
\text { images }\end{array}$ & $\begin{array}{l}\text { Comparison of portal } \\
\text { phase and Multi- } \\
\text { phase using } 95 \text { cases. } \\
\text { Hemangioma } \\
(56 \text { to63\%), } \\
\text { HCC (31to50\%). } \\
\text { Adenoma }(5 \text { to } 8 \%)\end{array}$ & $\begin{array}{l}\text { Classificatio } \\
\mathrm{n} \text { of liver } \\
\text { lesion }\end{array}$ \\
\hline $\begin{array}{l}\text { O. Fekry Abd-Elaziz, } \\
\text { M. Sharaf Sayed }\end{array}$ & $\begin{array}{l}\text { Region Growing Technique } \\
\text { for segmentation }\end{array}$ & $\begin{array}{l}99.7 \% \text { accuracy on } \\
15 \text { cases. }\end{array}$ & $\begin{array}{l}\text { Detection } \\
\text { and } \\
\text { segmentatio } \\
\text { n of liver } \\
\text { tumor }\end{array}$ \\
\hline Luyao Wang & $\begin{array}{l}\text { Tumor is detected by } \\
\text { experienced radiologists } \\
\text { manually, } \\
\text { Features are extracted from } \\
\text { ROI. } \\
\text { SVM is labeling and } \\
\text { classification }\end{array}$ & $\begin{array}{l}97.78 \% \text { accuracy on } \\
90 \text { ROI's }\end{array}$ & $\begin{array}{l}\text { Classificati } \\
\text { on of liver } \\
\text { lesion }\end{array}$ \\
\hline $\begin{array}{l}\text { S.S Kumar } \\
\text { Moni }\end{array}$ & $\begin{array}{l}\text { FCM clustering for } \\
\text { segmentation } \\
\text { Fast Discrete Curvelet } \\
\text { Transform to extract feature } \\
\text { SVM for classification }\end{array}$ & $\begin{array}{l}93.3 \% \text { accuracy on } \\
45 \text { cases }\end{array}$ & $\begin{array}{l}\text { Classificati } \\
\text { on of liver } \\
\text { lesion }\end{array}$ \\
\hline Gletsos Miltiades & $\begin{array}{l}\text { ROI identified manually } \\
\text { ROI result fee to the feature } \\
\text { extraction. }\end{array}$ & $\begin{array}{l}97 \% \text { for validation } \\
\text { set and } 100 \% \text { for } \\
\text { testing set }\end{array}$ & $\begin{array}{l}\text { Detect and } \\
\text { segment the } \\
\text { liver tumor }\end{array}$ \\
\hline Jae-Sung Hang & $\begin{array}{l}\text { FCM for segmentation } \\
\text { Circularity and Minimum }\end{array}$ & Accuracy of $91 \%$. & $\begin{array}{l}\text { Classificati } \\
\text { on of liver } \\
\text { lesion. }\end{array}$ \\
\hline
\end{tabular}




\begin{tabular}{|c|c|c|c|}
\hline & $\begin{array}{l}\text { for extraction } \\
\text { Naïve based classifier for } \\
\text { classification }\end{array}$ & & \\
\hline $\begin{array}{l}\text { K.Mala } \\
\text { V.Sadasivam }\end{array}$ & $\begin{array}{l}\text { Sequential backward } \\
\text { selection for feature } \\
\text { extraction } \\
\text { PNN for classification. }\end{array}$ & $\begin{array}{l}\text { Accuracy of } 90.2 \% \\
\text { on } 210 \text { cases. }\end{array}$ & $\begin{array}{l}\text { Classificati } \\
\text { on of liver } \\
\text { lesion. }\end{array}$ \\
\hline
\end{tabular}

4. Conclusion. Many techniques have been introduced for computer aided diagnosis of liver lesion. In this survey we have discussed the different techniques and methods of computer aided diagnosis. In the analysis table we see that the discussed techniques can segment and classify the liver CT image and can provide result precisely, efficiently and accurately. We have thoroughly studied, reviewed and analyzed at least ten algorithmic techniques for medical image processing [4]. These techniques are very powerful and have its strength in its own area. However segmentation, feature extraction and classification of the liver lesion are still a big challenge though a lot of work has been done already to refine the scan. There is still a lot of work to be done that will be discussed in future research. Different techniques are best in different phases like first technique has high accuracy in classification, the method discussed in second technique is better than watershed method; the method discussed third technique has optimal accuracy in image classification. Fifth method has accuracy up to hundred percent in most of the cases in detection and segmentation of liver lesion. Although every technique has its own advantages and disadvantages, so its upto the researcher to choose the technique based on his work. The techniques in methods six, seven, nine and ten are applied in classification and have different percentages of outcomes which are optimal in different cases. There are a number of techniques other than we discussed here. Each have its own advantages and disadvantages and have merits upon others but each method has its own worth. The further classification will be continued in future papers however no any is obsolete at all.

\section{REFERENCES}

[1] Mansoor, A., Bagci, U., Xu, Z., Foster, B., Olivier, K. N., Elinoff, J. M., ... \& Mollura, D. J. (2014). A generic approach to pathological lung segmentation. IEEE Trans. Med. Imaging, 33(12), 2293-2310.

[2] Brooks, R. A., \& Di Chiro, G. (1976). Statistical limitations in x-ray reconstructive tomography. Medical physics, 3(4), 237-240.

[3] Goryawala, M., Gulec, S., Bhatt, R., McGoron, A. J., \& Adjouadi, M. (2014). A low-interaction automatic 3D liver segmentation method using computed tomography for selective internal radiation therapy. BioMed research international, 2014.

[4] Programmed Identification AND Characterization OF LIVER Injuries FROM CT-Sweep Pictures. Ria Benny, Dr.Tessamma Thomas. Division of Electronics.Cochin College of Science And Innovation Cochin, India.

[5] IJRET: Universal Diary of Exploration in Building and Innovation eISSN: 2319-1163 | pISSN: 23217308.Volume: 02 Issue: 12 | Dec-2013, Accessible @ http://www.ijret.org 84.COMPUTER Helped Conclusion FOR LIVER Growth Utilizing Factual MODEL.Vincey Jeba Malar.V1, Saravana Kumar. E2.

[6] Abd-Elaziz, O. F., Sayed, M. S., \& Abdullah, M. I. (2014, April). Liver tumors segmentation from abdominal $\mathrm{CT}$ images using region growing and morphological processing. In Engineering and Technology (ICET), 2014 International Conference on (pp. 1-6). IEEE.

[7] Gunasundari, S., \& Janakiraman, S. (2013). A study of textural analysis methods for the diagnosis of liver diseases from abdominal computed tomography. International Journal of Computer Applications, 74(11).

[8] Huang, W., Li, N., Lin, Z., Huang, G. B., Zong, W., Zhou, J., \& Duan, Y. (2013, July). Liver tumor detection and segmentation using kernel-based extreme learning machine. In Engineering in medicine and biology society (EMBC), 2013 35th annual international conference of the IEEE (pp. 3662-3665). IEEE.

[9] Chen, E. L., Chung, P. C., Chen, C. L., Tsai, H. M., \& Chang, C. I. (1998). An automatic diagnostic system for CT liver image classification. IEEE Transactions on Biomedical Engineering, 45(6), 783-794. 
[10] Seo, K. S. (2005, May). Improved fully automatic liver segmentation using histogram tail threshold algorithms. In International Conference on Computational Science (pp. 822-825). Springer, Berlin, Heidelberg.

[11] Rajendran, A., \& Dhanasekaran, R. (2012). Fuzzy clustering and deformable model for tumor segmentation on MRI brain image: a combined approach. Procedia Engineering, 30, 327-333.

[12] Safdari, M., Pasari, R., Rubin, D., \& Greenspan, H. (2013, March). Image patch-based method for automated classification and detection of focal liver lesions on CT. In Medical Imaging 2013: Computer-Aided Diagnosis (Vol. 8670, p. 86700Y). International Society for Optics and Photonics.

[13] Dankerl, P., Cavallaro, A., Tsymbal, A., Costa, M. J., Suehling, M., Janka, R., ... \& Hammon, M. (2013). A retrieval-based computer-aided diagnosis system for the characterization of liver lesions in CT scans. Academic radiology, 20(12), 1526-1534.

[14] Entezari-Maleki, R., Rezaei, A., \& Minaei-Bidgoli, B. (2009). Comparison of classification methods based on the type of attributes and sample size. Journal of Convergence Information Technology, 4(3), 94-102.

[15] Yang, M. S., Hu, Y. J., Lin, K. C. R., \& Lin, C. C. L. (2002). Segmentation techniques for tissue differentiation in MRI of ophthalmology using fuzzy clustering algorithms. Magnetic Resonance Imaging, 20(2), 173-179. 